\title{
Effects of Weight Consciousness, Circadian Arousal, and Depression on Young Women's Memory
}

\author{
Christie Chung, Frishta Sharifi, Sara Harris \\ Psychology Department, Mills College, Oakland, USA. \\ Email: cchung@mills.edu \\ Received July 19 $9^{\text {th }}, 2011$; revised August 25 $5^{\text {th }}, 2011$; accepted September $26^{\text {th }}, 2011$.
}

\begin{abstract}
Weight consciousness has been found to significantly affect women's cognitive performance. In the present study, the effects of circadian arousal and depression were investigated by examining the relationship between young women's weight consciousness and memory performance. College women were tested on a picture recall task consisting of neutral and weight-related pictures. Participants were categorized into morning, evening, and intermediate types, and were tested either in the morning or late afternoon/evening (peak and non-peak testing times, or control). Our results showed that participants who were weight conscious were also more depressed. When tested at non-peak times, depressed participants recalled significantly more weight-related pictures than neutral pictures, while non-depressed participants did not show this recall pattern. These results suggest that young women with depression are less likely to inhibit memory of weight-related pictures when tested at their non-peak times of the day.
\end{abstract}

Keywords: Memory, Women, Weight Consciousness, Circadian Arousal, Depression

\section{Introduction}

"I'm on a diet" is a common phrase among women. Although not everyone who goes on a diet eventually develops an eating disorder, simply being weight conscious has been found to pose serious threats to an individual's cognition. For example, Cooper, Deepak, Groscutt, and Bailey (2007) found that the experience of "feeling fat" was greatly associated with distress, negative emotions, and first memory of feeling fat. Weight-preoccupied women were also more likely to negatively interpret an ambiguous figure related to body size and to remember these stimuli in later memory tests (Jackman, Williamson, Netemeyer, \& Anderson, 1995). The present study examined the effects of weight consciousness, circadian arousal, and depression on young women's memory for weight-related and neutral information.

\section{Weight Consciousness and Memory}

Tekcan, Tas, Topçuoglu, and Yücel (2008) found that anorexic patients had more difficulty than controls in inhibiting eating disorder-related words in a directed forgetting paradigm in which they were told to either remember or forget certain stimuli. This finding suggests that eating disorders may take up limited cognitive resources that are available for processing important information such as rehearsing a phone number for later recall. In a related paradigm, Kemps and Tiggemann (2005) showed that women who were dieting for weight-loss had significant executive functioning deficits, but not storage capacity of the phonological loop and visual-spatial sketchpad (Baddeley \& Hitch, 1974). Dieters were also shown to be more pre-occupied with food-related thoughts than non-dieters, which subsequently contributed to the executive functioning deficits observed (Green et al., 2003; Green \& Rogers, 1998; Jones \& Rogers, 2003; Shaw \& Tiggemann, 2004; Vreugdenburg, Bryan, \& Kemps, 2003). Kemps and Tiggemann's (2005) study, along with several other studies in the area suggest that weight consciousness affects executive functioning (Green et al., 2003; Vreugdenburg et al., 2003; Kemps, Tiggemann, \& Grigg, 2009), which could subsequently translate into inhibition deficit and memory problems. Similarly, Kemps, Tiggemann, \& Griggs (2009) also found that food cravings (e.g., chocolate cravings) significantly affect participants' direction to craving-related cues. This effect is especially salient for habitual food cravers. Based on these previous findings, the present study tested the hypothesis that participants who were more weight conscious as measured on the Eating Attitude Test (EAT; Garner, Olmsted, Bohr, \& Garfinkel, 1982) would be more likely to direct attention to weight-related stimuli; and thus, have better recall for weight-related stimuli than for neutral stimuli.

\section{Circadian Arousal and Memory}

Circadian arousal, the 24-hour cycle seen in cognitive functioning (Folkard, 1982), has also been found to interact with executive functioning, especially inhibition processing (e.g., May \& Hasher, 1998; Hasher, Chung, May, \& Foong, 2002). Circadian rhythms usually reflect 24-hour cycles of changes in biological and physiological functions, such as body temperature, heart rate, and hormone secretion (e.g., Hrushesky, 1994; Moore-Ede, Sulzman, \& Fuller, 1982). Researchers have found similar 24-hour cycles in cognitive functioning that are substantially moderated by reliable individual differences (e.g., Anderson, Petros, Beckwith, Mitchell, \& Fritz, 1991; Petros, Beckwith, \& Anderson, 1990; Yoon, 1997; Yoon, May, \& Hasher, 1998). In general, people can be classified into morning-type, evening-type, or intermediate-type by the Morningness-Eveningness Questionnaire (MEQ; Horne \& Ostberg, 1976). Inhibition tasks are performed with higher accuracy when participants are tested at their peak (i.e., morning-type tested in morning, and evening-type tested in evening) rather than nonpeak (i.e., morning-type tested in the evening, and evening-type tested in morning) times of the day-a synchrony effect (Hasher, Zacks, \& May, 1999).

According to Hasher et al. (1999), inhibitory attentional 
processes regulate the flow of information from both thought and perception by 1) limiting access to consciousness to goal relevant information; 2) deleting irrelevant and no longer relevant information from consciousness; and 3) restraining strong responses so they can be evaluated for appropriateness. Each of these functions has been shown to be more efficient when participants were tested at peak as compared to non-peak times of day and are subsequently implicated in participants' memory recall and recognition performance (see e.g., May 1999; May \& Hasher, 1998; Yoon et al., 1998).

\section{Weight Consciousness, Circadian Arousal, and Memory}

In the present study, the effects of weight consciousness and circadian arousal on memory were examined in young college women, aged 18 to 30 . Specifically, we examined whether young women's memory for weight-related stimuli would be influenced by their level of weight consciousness and the time of experimental testing. The primary hypothesis was that weight conscious young women tested at their non-peak times would be more likely than non-weight conscious women tested at their peak times to recall stimuli weight-related than neutral stimuli. Since depression has also been found to significantly correlate with weight-related issues and eating disorders (e.g., Cooper et al., 2007; Jackman et al., 1995; Koenig \& Wasserman,1995; Smoller, Wadden, \& Stunkard, 1987), and to significantly decrease inhibition (Joorman, 2010), the effect of depression status on memory performance was also examined. We hypothesized that depressed women who were weight conscious would have more difficulty recalling weight-related information at non-optimal times of the day than those who are non-depressed and non-weight-conscious.

\section{Method}

\section{Participants}

Eighty-six young women (aged 18 - 30) from Mills College in Oakland, California participated in this study. All participants were recruited through email postings, flyers, and undergraduate classes at Mills College, Oakland, California, USA. Participants received either course credit or US\$10 for participation. Participants were screened on the phone or through e-mail for psychological and neurological disorders (Table 1).

The Morningness-Eveningness Questionnaire (MEQ; Horne \& Ostberg, 1976) was administered before participation in the experiment to determine participants' circadian arousal (morning-, evening-, or intermediate-type). Of the 86 participants, 14 were tested at their peak times (morning-type tested in morning: 8 a.m. to 10 a.m.; or evening-type tested in late afternoon/evening: 5 p.m. to 7 p.m.); 19 at their non-peak time (evening-type in morning; or morning-type in late afternoon/evening), and 53 were controls (intermediate-type tested in the morning or late afternoon).

\section{Design and Materials}

The picture recall task consisted of 15 weight-related pictures (food, clothing, scenes, objects, and equipment) and 15 matched neutral pictures, with 2 filler pictures at the beginning and end of each encoding list. These pictures were equated on complexity, resolution (72 pixel/inch), and size (width: 12inches, height: 10inches). The pictures were obtained from the internet and were rated for weight-relatedness by a separate group of young
Table 1.

Means and (SD's) for demographics and cognitive measures.

\begin{tabular}{cccc}
\hline Measure & $\begin{array}{c}\text { Non-peak } \\
(\boldsymbol{n}=\mathbf{1 4})\end{array}$ & $\begin{array}{c}\text { Peak } \\
(\boldsymbol{n}=\mathbf{1 9 )}\end{array}$ & $\begin{array}{c}\text { Control } \\
(\boldsymbol{n}=\mathbf{5 3})\end{array}$ \\
\hline Age & 20.07 & 22.00 & 20.17 \\
& $(2.165)$ & $(5.217)$ & $(3.327)$ \\
Years of Education & 14.15 & 14.05 & 14.09 \\
& $(1.345)$ & $(2.615)$ & $(1.154)$ \\
Body Mass Index & 23.48 & 24.15 & 24.14 \\
& $(4.39)$ & $(4.33)$ & $(4.65)$ \\
Beck Depression & 6.79 & 5.79 & 7.85 \\
Inventory & $(7.718)$ & $(5.603)$ & $(6.234)$ \\
Eating & 9.00 & 6.05 & 5.22 \\
Attitudes Test & $(11.629)$ & $(5.710)$ & $(5.213)$ \\
Letter Number & 11.29 & 11.16 & 11.91 \\
Sequencing & $(2.431)$ & $(1.573)$ & $(2.102)$ \\
Frequency of & $43.07^{*}$ & 49.74 & 48.00 \\
Forgetting & $(8.508)$ & $(6.707)$ & $(8.733)$ \\
\hline
\end{tabular}

Note: ${ }^{*} p<.05$. Although participants tested at non-peak times had significantly lower Frequency of Forgetting scores than controls and peak times participants, the three groups did not differ significantly on overall memory performance (Figure 1).

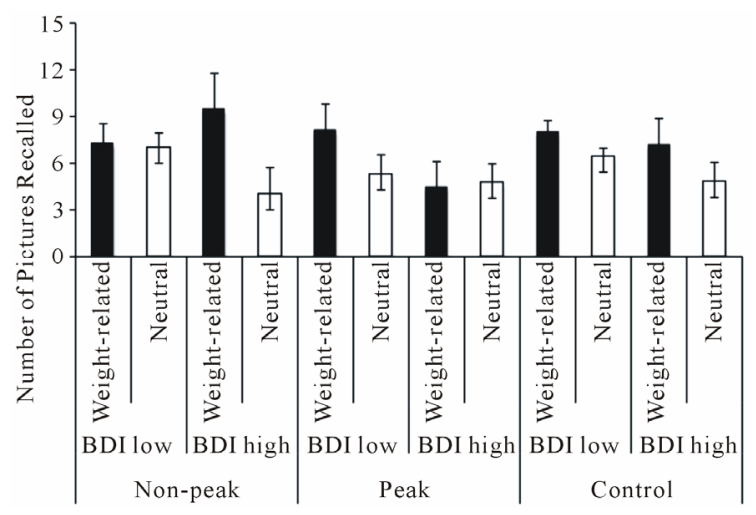

Figure 1.

Young women's memory performance by picture type (neutral vs. weightrelated), BDI scores (high vs. low), and testing times (peak, non-peak, and control).

women ( $n=30$; see Appendix). Two counterbalanced lists were created with these pictures.

\section{Procedure}

Participants were tested individually in a quiet laboratory testing room and were seated in front of a 17-inch computer screen. Viewing distance from the computer screen was about 30 inches and could be adjusted for participants' comfort. After completing the informed consent form, participants completed a health and demographic questionnaire, on which they also self-reported their height and weight.

Then, participants were randomly assigned to either one of the counterbalanced conditions of the picture task. Participants were instructed to view each picture carefully (presented at a rate of $4 \mathrm{sec} /$ picture) and rate the valence and arousal of each picture on a 9-point scale. For the valence scale, $1=$ very negative and $9=$ very positive; and for the arousal scale, $1=$ very exciting to $9=$ very calming. Participants responded to each picture by pressing a number between 1 and 9 on the keyboard. Participants were not told that a memory test would follow. After receiving oral instructions about this picture task, partici- 
pants completed a practice task consisting of 6 unrelated, neutral encoding pictures. This practice task was designed to familiarize the participants with the actual picture task.

All pictures were presented on a black background. Each trial started with the presentation of a picture for 4 seconds, followed by a black background screen with the 9-point valence scale in white. The arousal scale appeared only if a response to the valence scale was entered. Once the arousal response was entered, the next picture trial of 4 seconds began. If a valence or arousal response was not entered after 10 seconds (classified as timeout), the next picture automatically appeared on the screen.

After this picture task, a filled delay period of approximately $5 \mathrm{~min}$ followed, where the Letter Number Sequencing task (Wechsler, 1997) was administered. Then participants were asked to recall as many pictures as they could remember from the study phase using brief verbal descriptions. Verbal descriptions were recorded on paper by the experimenter. Participants then completed a personality questionnaire (NEO-FFI; Costa \& McCrae, 2003), the Eating Attitudes Test (EAT; Garner, Olmsted, Bohr, \& Garfinkel, 1982) — a screening measure for eating disorders, the Beck Depression Inventory (BDI; Beck, Ward, Mendelson, Mock, \& Erbaugh, 1961) - to determine the participants' depression status, and the Frequency of Forgetting questionnaire (Zelinsky \& Gilewsky, 2004) — for metamemory analysis.

After completion of the tasks, participants were debriefed and given the option to stand on a weighing scale to have their actual weight measured. Participants' actual or self-reported weights were then used to calculate their body mass indices: $\mathrm{BMI}=$ [weight in pounds/(height in inches $) \times($ height in inches) $\times$ 703]. The entire experimental session lasted approximately one hour.

\section{Results}

Data analyses were conducted using the statistical software SPSS (PASW) 18.0. Participants were categorized into high and low BDI and EAT groups by the following criteria: EAT/BDI low: 0 to 10, EAT/BDI high: 11 and above. Higher scores on BDI and EAT represent higher rates of depression and weight consciousness. BDI and EAT scores were significantly correlated with each other, $r(86)=3.12, p<.01$. BMI did not correlate significantly with any other measures and were similar across testing conditions (Table 1). Participants' picture recall data were first analyzed using a 3 (testing time: peak, non-peak, control) $\times 2$ (picture type: weight-related vs. neutral $) \times 2($ EAT: low vs. high $) \times 2($ BDI: low vs. high $)$ mixed factorial ANOVA. The three-way interaction between picture type $\mathrm{x}$ BDI $\mathrm{x}$ testing time was significant, $F(2,77) 3.32, p<.05$, $\eta^{2}=.08$. The main effect of picture type was also significant, $F(1,77) 11.07, p<.01, \eta^{2}=.13$.

Separate t-test analyses were conducted for each testing condition to further investigate the significant three-way interaction (Figure 1). For control participants, both low and high BDI participants did not differ significantly in their recall of weight-related and neutral pictures, $t(41)=2.31, p<.03 ; t(12)$ $=2.64, p<.03$, respectively. Non-depressed (low BDI) participants tested at peak times, recalled slightly more weight-related pictures than neutral pictures, $M \mathrm{~s}=8.27 \mathrm{vs}$. 7.27, although this difference did not reach statistical significance, $t(14)=1.37, p$ $=.19$. Participants with high BDI scores did not show this difference, $M s=4.50$ vs. $4.75 ; t(3)=1.74, p=.87$. At non-peak testing times, participants with high BDI scores recalled sig- nificantly more weight-related pictures than neutral pictures, $M s=9.50$ vs. $4.00 ; t(1)=3.67, p=.17$, while participants with low BDI scores did not show this statistical significance, $M \mathrm{~s}=$ 8.17 vs. $7.00 ; t(1)=1.03, p=.33$.

\section{Discussion}

The results from the present study showed that weight consciousness and depression were highly correlated; although only depression, not weight consciousness, significantly influenced memory performance. During peak testing times, participants did not differ in their recall for weight-related and neutral pictures, regardless of depression status. However, during non-peak testing times, only non-depressed participants did not differ in their recall of weight-related or neutral pictures. Depressed participants recalled significantly more weight-related than neutral pictures. Thus, peak testing times allowed participants to focus their cognitive resources on suppressing weight-related information; while being tested in the non-peak hours greatly hindered depressed participants' ability to suppress weight-related information.

\section{Weight Consciousness and Memory}

The findings in this study are novel and interesting. Contrary to our hypothesis, weight consciousness as measured by the Eating Attitude Test (EAT) was not significantly related to our participants' memory recall for weight-related and neutral stimuli in this study. Past studies have shown that cognition may be affected by participants' dieting status (Kemps \& Tiggemann, 2005), food craving status (Kemps \& Tiggemann, 2009), body image perception (Cooper et al., 2007; Jackman et al., 1995), and eating disorder condition (Tekcan et al., 2008). Although the present results did not directly show a link between weight consciousness and memory, there is reason to believe that weight consciousness may be implicated in the overall pattern of results because of the significant positive correlation between EAT and BDI scores. Many studies have demonstrated a significant correlation between the weight consciousness and depression (e.g., Cooper et al., 2007; Jackman et al., 1995; Koenig \& Wasserman,1995; Smoller, Wadden, \& Stunkard, 1987), yet, only a few studies have directly examined the impact of these two factors on women's cognition simultaneously (Hunt \& Cooper, 2001). The present results suggest that many of the previous findings relating weight issues with cognition could be explained by the depression status associated with participants' weight concerns. Further studies are necessary to tease apart the effects of these two variables.

\section{Depression and Memory}

Several mood-induction studies have shown that negative affect increases accuracy in retrieval (Storbeck \& Clore, 2005); while positive states reduce recall accuracy by decreasing processing capacity (Ruder \& Bless, 2003; Mackie \& Worth, 1989) and reducing processing motivation (Wegener \& Petty, 1994). Affective states have also been shown to increase the accessibility of mood-congruent material (Bower, 1981). Depression is a disorder characterized by difficulty in regulating mood states, and thus, understanding the complex interaction between mood and memory is important when interpreting the results of the present study.

Depression gives rise to difficulties in cognitive control, which leads to deficit in memory for non-emotional information (Burt, Zembar, \& Niederehe, 1995; Hertel, 2004). However, 
Hertel (2004) found that depressed participants' deficit in recall is not likely to be a cognitive deficit because when the opportunity to ruminate was eliminated, depressed and non-depressed participants performed similarly. Hertel's (2004) finding can therefore be related to the literature on cognitive control and inhibition-depressed participants are more likely to focus their attention on irrelevant information and thus, exhibit inhibition deficit on cognitive tasks (Hasher \& Zacks, 1988).

Depression may also make negative material more accessible and positive material less accessible - mood congruency (Matthews \& MacLeod, 2005). Many studies have presented results consistent with this framework (see Blaney, 1986; Matt, Vazquez, \& Campbell, 1992). In a meta-analysis, Matt et al. (1992) found that depressed participants remember $10 \%$ more negative than positive words. Non-depressed participants, on the other hand, showed a positive bias in 20 out of 25 studies. Using a Deese-Roediger-McDermott paradigm, Joormann, Teachman, and Gotlib (2009) also found a link between depression and false recall of negative material.

Why does depression lead to increased negative recall? Joormann (2010) presented a comprehensive overview of this literature and proposed a direct relation between depression and inhibition deficit of negative material. As mentioned in our introduction, inhibition serves three specific functions in consciousness: it limits access to goal relevant information; deletes irrelevant information; and restrains strong and viable responses for later evaluation (Hasher et al., 1999). Joormann (2010) proposed that depression interferes with one's ability to prevent negative, mood-congruent, material from accessing working memory, which may lead to rumination of negative information.

\section{Depression, Circadian Arousal, and Memory}

The present study is the first to demonstrate an effect of depression on circadian arousal and memory. Based on the synchrony effect (Hasher et al., 1999), participants tested at peak times should perform more optimally on cognitive inhibitory tasks than those tested at non-peak times. The present results further extended this finding as the circadian arousal effect interacted with participants' depression status. Depressed participants who were tested at non-peak times recalled significantly more weight-related than neutral pictures. However, depressed participants who were tested at peak times did not show this recall difference. One explanation for this pattern of result is that non-depressed participants tested at peak times were better able to inhibit weight-related information than depressed participants tested at non-peak times of the day. The control participants showed a significant recall bias for weight-related pictures, regardless of depression status. This suggests that the weight-related pictures may have been inherently more memorable to begin with. Even with this starting point, however, there were significantly different patterns of picture recall in participants tested at peak and non-peak times.

According to the synchrony effect (Hasher et al., 1999), participants tested at peak hours of the day are more likely to utilize inhibition cognitively. If weight-related information was what the depressed participants tried to inhibit (given the significant correlation between depression and weight consciousness), then the synchrony effect explanation could be applied to explain the present findings. Namely, depressed participants were more likely to suffer from inhibition deficit of moodcongruent material when tested at non-peak hours of the day. This hypothesis is further supported by the finding that non-depressed participants tested at peak times, who are supposedly more capable in utilizing inhibition to filter out weight-related materials, recalled significant more neutral than weight-related pictures.

The results from this study are critical in understanding weight conscious and depressed women's cognitive ability in academic and work settings. Young adults are often required to attend school or work during hours that are not necessarily cognitively optimal for them. This study sheds light on the negative cognitive consequences that such a schedule could have on depressed young women with regards to weight-related materials. Future research will extend the present findings by examining interactions of depression and weight consciousness in memory processes around the 24-hour clock. Men and older adults will also be tested in follow-up studies to examine the generalizability of the present results.

\section{Acknowledgements}

This project was funded by a Meg Quigley Women's Fellowship and a Mills College Faculty Research Grant. We thank Sara A. Wong for her assistance in programming the experiment and Ekaterina Mahinda for her help in testing participants.

\section{References}

Anderson, M. J., Petros, T. V., Beckwith, B. E., Mitchell, W. W., \& Fritz, S. (1991). Individual differences in the effect of time of day on long-term memory access. American Journal of Psychology, 104, 241-255. doi: $10.2307 / 1423157$

Baddeley, A. D., \& Hitch, G. J. (1974). Working memory. In G. H. Bower (Ed.), The psychology of learning and motivation (Vol. 8). New York: Academic Press.

Beck, A. T., Ward, C. H., Mendelson, M., Mock, J., \& Erbaugh, J. (1961). An inventory for measuring depression. Archives of General Psychiatry, 4, 1961, 561-571.

Blaney, P. H. (1986). Affect and memory: A review. Psychological Bulletin, 99, 229-246. doi:10.1037/0033-2909.99.2.229

Bower, G. H. (1981). Mood and memory. American Psychologist, 36, 129-148. doi:10.1037/0003-066X.36.2.129

Burt, D. B., Zembar, M. J., \& Niederehe, G. (1995). Depression and memory impairment: A meta-analysis of the association, its pattern, and specificity. Psychological Bulletin, 117, 285-305. doi: 10.1037/0033-2909.117.2.285

Costa, P. T. \& McCrae, R. R. (2003). Neo Five Factor Inventory (NEO-FFI). Lutz, FL: Psychological Assessment Resources, Inc.

Cooper, M. J., Deepak, K., Groscutt, E., \& Bailey, E. (2007). The experience of "feeling fat" in women with anorexia nervosa, dieting and non-dieting women: An exploratory study. European Eating Disorders Review, 15, 366-372. doi:10.1002/erv.785

Folkard, S. (1982). Circadian rhythms and human memory. In F. M. Brown, \& R. C. Graeber (Eds.), Rhythmic aspects of behavior (pp. 241-272). Hillsdale, NJ: Lawrence Erlbaum Associates.

Garner, D. M., Olmsted, M. P., Bohr, Y., \& Garfinkel, P. E. (1982). The eating attitudes test: Psychometric features and clinical correlates. Psychological Medicine, 12, 871-878. doi:10.1017/S0033291700049163

Green, M. W., Jones, A. D., Smith, I. D., Cobain, M. R., Williams, J. M. G., Healy, H., Cowen, P. J., Powell, J., \& Durlach, P. J. (2003). Impairments in working memory associated with naturalistic dieting in women: No relationship between task performance and urinary 5-HIAA levels. Appetite, 40, 145-153. doi: 10.1016/S0195-6663(02)00137-X

Green, M. W., \& Rogers, P. J. (1998). Impairments in working memory associated with spontaneous dieting behaviour. Psychological Medicine, 28, 60-68. doi:10.1017/S0033291798007016

Hasher, L., Chung, C., May, C., Foong, N. (2002). Age, time of testing, and proactive interference. Canadian Journal of Experimental Psy- 
chology, 56, 200-207. doi:10.1037/h0087397

Hasher, L., \& Zacks, R. T. (1988). Working memory, comprehension, and aging: A review and a new view. In G. H. Bower (Ed.), The psychology of learning and motivation (Vol. 22 pp. 193-225). San Diego, CA: Academic Press.

Hasher, L., Zacks, R. T., \& May, C. P. (1999). Inhibitory control, circadian arousal, and age. In D. Gopher, \& A. Koriat (Eds.), Attention and performance, XVII, cognitive regulation of performance: Interaction of theory and application (pp. 653-675). Cambridge, MA: MIT Press.

Hertel, P. T. (2004). Memory for emotional and nonemotional events in depression: A question of habit? In D. Reisberg, \& P.Hertel (Eds.), Memory and emotion (pp. 186-216). New York: Oxford University Press.

Horne, J., \& Ostberg, O. (1977). Individual differences in human circadian rhythms. Biological Psychology, 5, 179-190. doi:10.1016/0301-0511(77)90001-1

Hunt, J. \& Cooper, M. (2001). Selective memory bias in women with bulimia nervosa and women with depression. Behavioural and Cognitive Psychotherapy, 29, 93-102. doi:10.1017/S1352465801001102

Hrushesky, W. (1994). Timing is everything. The Sciences, 34, 32-37.

Jackman, L. P., Williamson, D. A., Netemeyer, R. G., \& Anderson, D. A. (1995). Do weight-preoccupied women misinterpret ambiguous stimuli related to body size? Cognitive Therapy and Research, 19, 341-355. doi:10.1007/BF02230404

Jones, N., \& Rogers, P. J. (2003). Preoccupation, food, and failure: An investigation of cognitive performance deficits in dieters. International Journal of Eating Disorders, 33, 185-192. doi:10.1002/eat.10124

Joormann, J. (2010). Cognitive inhibition and emotion regulation in depression. Current Directions in Psychological Science, 19, 161166. doi: $10.1177 / 0963721410370293$

Joormann, J., Teachman, B. A., \& Gotlib, I. H. (2009). Sadder and less accurate? False memory for negative material in depression. Journal of Abnormal Psychology, 118, 412-417. doi:10.1037/a0015621

Kemps, E., \& Tiggeman, M. (2005). Working memory performance and preoccupying thoughts in female dieters: Evidence for a selective central executive impairment. British Journal of Clinical Psychology, 44, 357-366. doi:10.1348/014466505X35272

Kemps, E., \& Tiggemann, M. (2009). Attentional bias for craving-related (chocolate) food cues. Experimental and Clinical Psychopharmacology, 17, 425-433. doi:10.1037/a0017796

Kemps, E., Tiggemann, M., \& Grigg, M. (2008). Food cravings consume limited cognitive resources. Journal of Experimental Psychology: Applied, 14, 247-254. doi:10.1037/a0012736

Koenig, L. J., \& Wasserman, E. L. (1995). Body image and dieting failures in college men and women: Examining links between depression and eating problems. Sex Roles, 32, 225-249. doi:10.1007/BF01544790

Mackie, D. M. \& Worth, L. T. (1989). Processing deficits and the mediation of positive affect in persuasion. Journal of Personality and Social Psychology, 57, 27-40. doi:10.1037/0022-3514.57.1.27

Mathews, A., \& MacLeod, C. (2005). Cognitive vulnerability to emotional disorders. Annual Review of Clinical Psychology, 1, 167-195. doi:10.1146/annurev.clinpsy.1.102803.143916

Matt, G. E., Vazquez, C. \& Campbell, W. K. (1992). Mood-congruent recall of affectively toned stimuli: A meta-analytic review. Clinical

\section{Appendix}

Sample weight-related pictures:
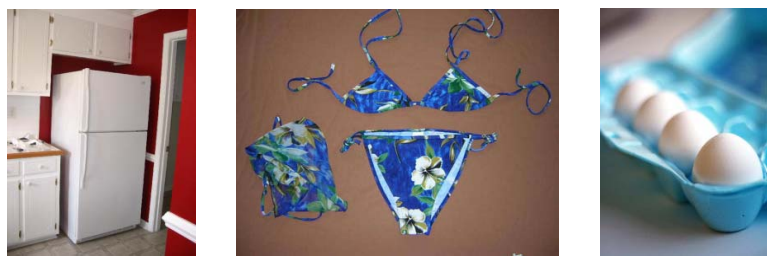

Psychology Review, 12, 227-255.

doi:10.1016/0272-7358(92)90116-P

May, C. P. (1999). Synchrony effects in cognition: The costs and a benefit, Psychonomic Bulletin \& Review, 6, 142-147.

doi: 10.3758/BF03210822

May, C. P., \& Hasher, L. (1998). Synchrony effect in inhibitory control over thought and action. Journal of Experimental Psychology: Human Perception and Performance, 24, 363-379. doi:10.1037/0096-1523.24.2.363

Moore-Ede, M. C., Sulzman, F. M., \& Fuller, C. A. (1982). The clocks that time us: Physiology of the circadian timing system. Cambridge, MA: Harvard University Press.

Petros, T. V., Beckwith, W., \& Anderson, M. (1990). Individual differences in the effects of time of day and passage difficulty on prose memory in adults. British Journal of Psychology, 81, 63-72. doi:10.1111/j.2044-8295.1990.tb02346.x

Ruder, M., \& Bless, H. (2003). Mood and the reliance on the ease of retrieval heuristic. Journal of Personality and Social Psychology, 85, 20-32. doi: 10.1037/0022-3514.85.1.20

Sharifi, F., Chung, C., Mahinda, E., Johnson, J., \& Wong, S. A. (2011). Emotional memory in women: Why a negativity bias? Journal of Psychology and Behavioral Sciences, 22, 36-42.

Shaw, J., \& Tiggemann, M. (2004). Dieting and working memory: Preoccupying cognitions and the role of the articulatory control process. British Journal of Health Psychology, 9, 175-185. doi:10.1348/135910704773891032

Smoller, J. W., Wadden, T. A., \& Stunkard, A. J. (1987). Dieting and depression: A critical review. Journal of Psychosomatic Research, 31, 429-440. doi:10.1016/0022-3999(87)90001-8

Storbeck, J., \& Clore, G. L. (2005). With sadness comes accuracy; with happiness, false memory: Mood and the false memory effect. Psychological Science, 16, 785-791.

doi:10.1111/j.1467-9280.2005.01615.x

Tekcan, A. I., Tas, A. C., Topcuoglu, V., \& Yücel, B. (2008). Memory bias in anorexia nervosa: Evidence from directed forgetting. Journal of Behavior Therapy and Experimental Psychiatry, 39, 369-380. doi:10.1016/j.jbtep.2007.09.005

Vreugdenburg, L., Bryan, J., \& Kemps, E. (2003). The effect of self-initiated weight-loss dieting on working memory: The role of preoccupying cognitions. Appetite, 41, 291-300. doi:10.1016/S0195-6663(03)00107-7

Wechsler, D. (1981). Wechsler adult intelligence scale-revised. San Antonio: Psychological Corporation.

Wegener, D. T., \& Petty, R. E. (1994). Mood management across affective states: The hedonic contingency hypothesis. Journal of Personality and Social Psychology, 66, 1034-1048. doi:10.1037/0022-3514.66.6.1034

Yoon, C. (1997). Age differences in consumers' processing strategies: An investigation of moderating influences. Journal of Consumer Research, 24, 329-342. doi:10.1086/209514

Yoon, C., May, C. P., \& Hasher, L. (1998). Aging, circadian arousal patterns, and cognition. In N. Schwartz, D. Park, B. Knauper, \& S. Seymour (Eds.), Cognition, aging, and self-Reports (pp. 117-143) Washington, DC: Psychology Press.

Zelinski, E. M., \& Gilewski, M. J. (2004). A 10-item Rasch modeled memory self-efficacy scale. Aging and Mental Health, 8, 293-306. doi:10.1080/13607860410001709665

Sample neutral pictures (matched each weight-related picture above):
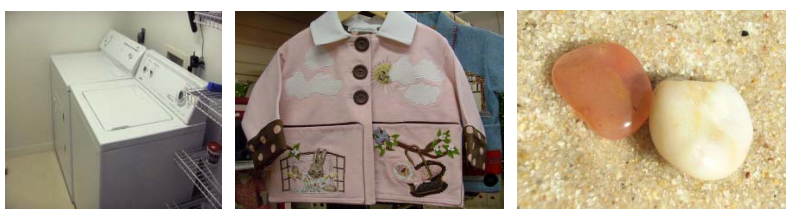